\title{
نقوش الجندى النوبى (ثهامو)
}

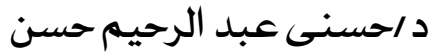 \\ مدير متحف النوبت}

حظيت لوحات النوبيين فن الجبلين بالعديد من الدراسات، واعتبرت مصدراً هاما

للدراسات عن الجنود النوبين الذين عملوا بالجيش المصري أبان عصر الانتقال الأول و الدولة الوسطى في الوقت الذي أثنارت فيه بحموعة من النقوش التي تركها الجندي النوبي (ثهامو) على صخور النوبة السفلى الكثير من الجدل حولها وربما كان ذلك يرجع إلى لطبيعة النقوش نفسها واحتمالية كوها بحرد أجزاء متبقية من نص كامل اختفى و هذا لا يقلل من أهميتها كمصدر عن دور النوبيين فن الجيش المصري وقبل البدء في هذه الدراسة

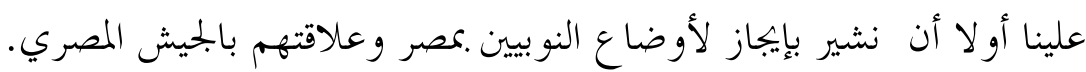
كانت العلاقات المصرية النوبية تتميز بأها موغلة في القدم وإن كانت بداياها بتحارية وتقوم

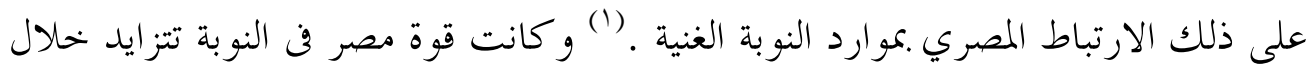
عصر الدولة القديمة وسرعان ما تحولت التجارة إلى استيلاء ثم إخضاع (ז) و و ظهرت المستعمرات المصرية فن النوبة والتي كانت تمثل مناطق استقرار لقاطنيها من التجار وعمال التعدين . (r) و كما أشار Adams "لقد كان عصر الدولة القديمة عصر اكتشاف تميز في

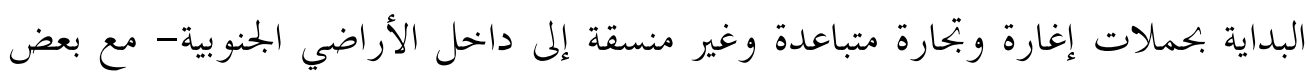

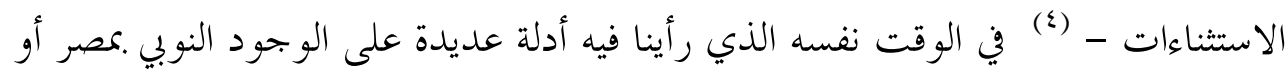

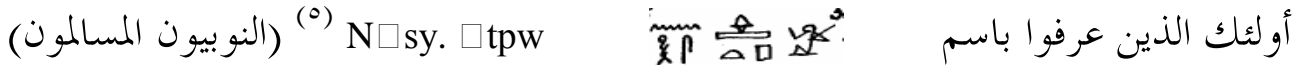
و الذين ذُكروا في مرسوم يى الأول بخصوص هرم سنفرو والذين يبدو أهم كانوا يعيشون

في المناطق المحاورة لمنف (T) 
وون النصف الأخير من الدولة القديمة وبدايات عصر الانتقال الأول رأينا أهم يشغلون العديد من الوظائف في المنازل وداخل الجيش كما يظهر من وصف "ونه ونى" لقوات أبيدوس:

$\square$ sf $\mathrm{n} \square \mathrm{m} . \mathrm{f} \square \mathrm{t} \mathrm{n}{ }^{\mathrm{c}} 3 \mathrm{mw} \square$ ryw $\square^{\mathrm{c}}{ }^{(14)}$ ir. $\mathrm{n} \square \mathrm{m}$.f $\mathrm{m}^{\natural} \mathrm{n} \mathrm{c} 3 \square \mathrm{b}^{\mathrm{c}} \mathrm{w} \mathrm{m} \square \mathrm{m}^{\mathrm{c}}$ mi kd.f $\square \mathrm{nt} \mathrm{m}$

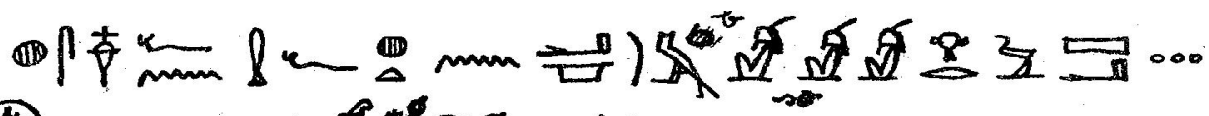
(14)

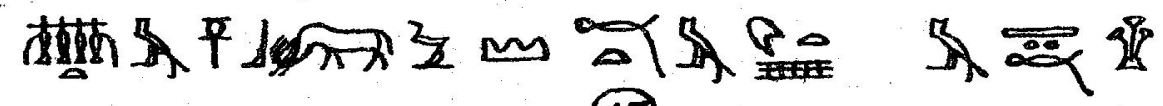

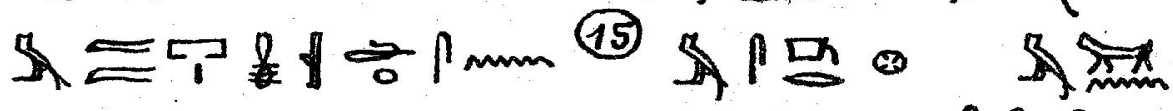

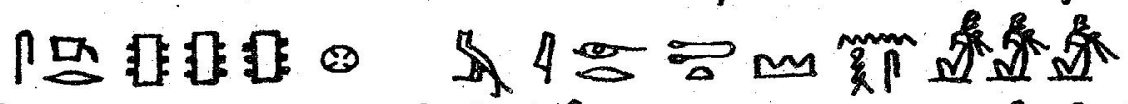

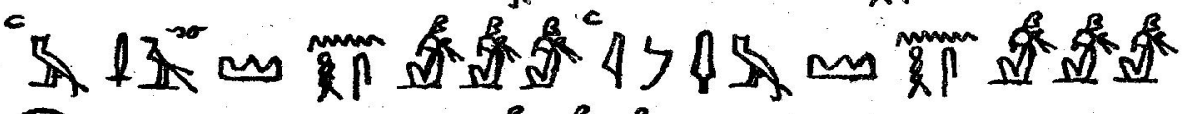
(16)

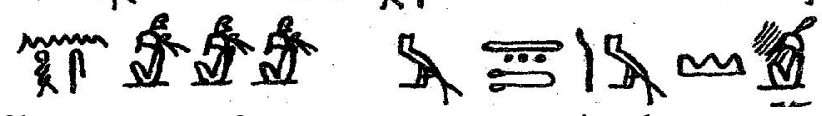

3bw m $\square$ t m t3 m $\square$ yt m gswy pr mi $\square$ d. sn m s $\square$ r m $\square$ nw s $\square$ r m ir $\square$ t n $\square$ sw m $\mathrm{m} \square 3 \mathrm{n} \square \mathrm{sw}$ i3m n $\square$ sw m w3w3t $\mathrm{n} \square$ sw m k3w n $\square$ sw m tm $\square$ w "جمع جيشاً من عشرات الآلاف من كل أرض مصر الجنوبية ، من "آبو" 3bw، في الجنوب إلي أطفيح في الشمال ، ومن مصر السفلي من جانب البيت كله ومن داخل المدن

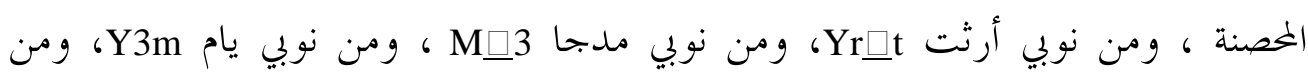

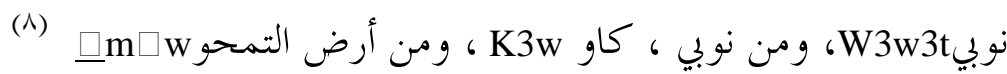
إن مصطلح "نحسيو" الذي ذكر بالنص كان يدل على كل ذوى البشرة الداكنة و وكان

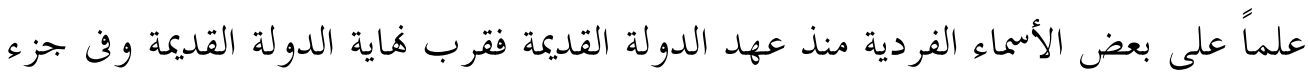
N N " "حسى "snb,N $\square$ sy $\square \mathrm{r} \square \mathrm{si}$ و الثلاثة يظهرون كحملة قرابين من مقاصير مصاطب الأسرة الخامسة وهناك ذكر أخر للنحسيو على لوحتين من بنع الدير ترجعان لعصر الانتقال الأول ومن الأسرة الحادية 
عشرة هناك ذكر لسيدتين من نوبي المجاى عملتا كخادمتين للزوجة الملكية عاشيت وظهرتا على تابوها. ور.بما تكون عاشيت نفسها نوبية على الرغم من أها لم تصرح بذلك. وهناك امرأة أخرى من دهشور حملت لقب نحسي عنخت ننى

استخدام لقب نحسيو مع الاسم الشخصي هنا بدا

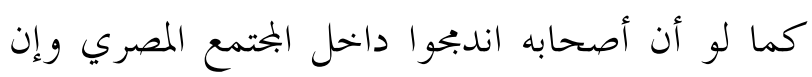

ظلو ا فخورين هويتهم الأصلية .على إن المدجاى على وجه التحديد الذين ذكروا في نص "ونى" لعبو ا دورا هاما في الجيش المصري فنحن نسمع عنهم طيلة الدولة القديمة وفى الدولة

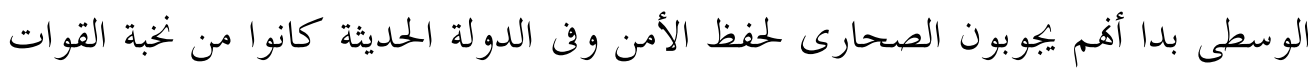

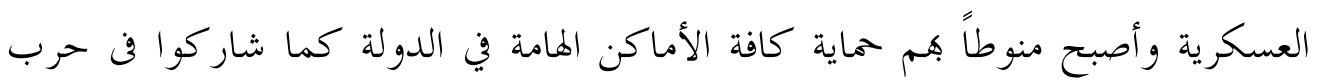
التحرير التى خاضها أحمس و لم يعد الاسم إشارة لمحموعة عرقية معينة، وبمرور الوقت أصبح لفظا شاملا لكل العاملين بالشرطة سواء كانوا من المدجاي أو غيرهم، وكوفم من من نخبة

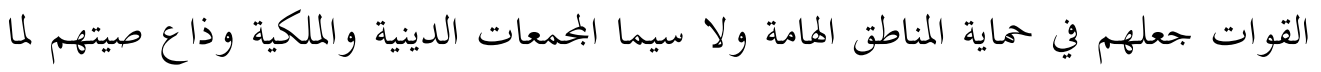

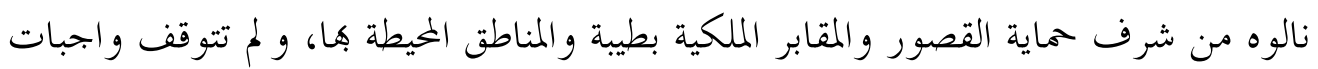
حماية المجاي للمناطق الواقعة بمصر العليا فقط بل امتد وجودهم حتى مصر السفلى أيضا،

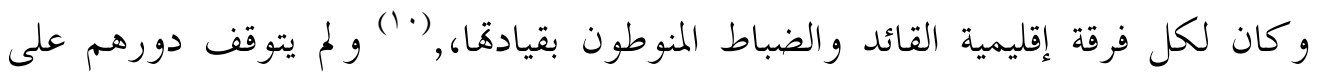
حماية المناطق الهامة داخل حدود المملكة المصرية فحسب، بل امتد دورهم ليشمل العمل كجنود كشافة لاستكشاف شعاب الصحراء في تلك الحقبة (1') في البداية أقتصر تكوين تلك الفرق العسكرية على المنحدرين من أصول البحاى القبلية القديمة وتغيرت الأمور مع الوقت بانضمام أعداد أكبر من المصريين للخدمة العسكرية في تلك الفرق و بالنظر للوثائق

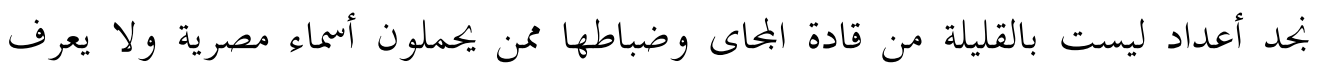
بالتحديد سبب ذلك التحول الكبير وأن أرجعه بعض علماء المصريات لنظرة المختمع المصري

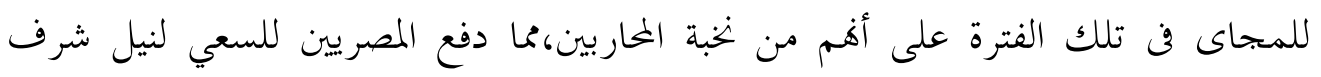
محاثل (1) مئج) 
يؤ كد هذا الرأي .ما أشار إليه " حرخوف " علي جدران مقبرته بغرب أسوان بأنه عاد

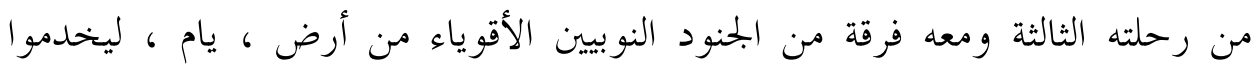
كجنود في الجيش المصري.

ثم بدأنا نسمع عن لقب

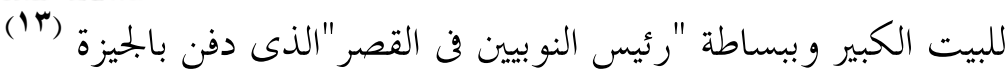

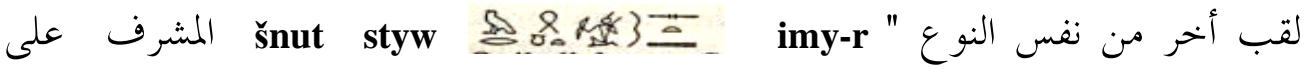
قوات النوبة" و.كميء الدولة الوسطى شهدت العلاقات المصرية النوبية تطورا ملحوظا وتبدلت السياسة المصرية بتحاه النوبة في الوقت نفسه الذي تغيرت فيه أوضاع النوبيين فن مصر، ويذهب Smith

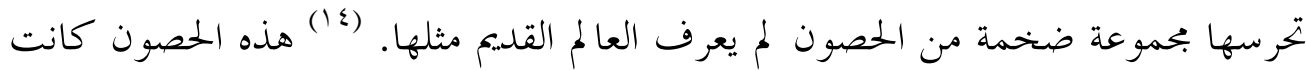

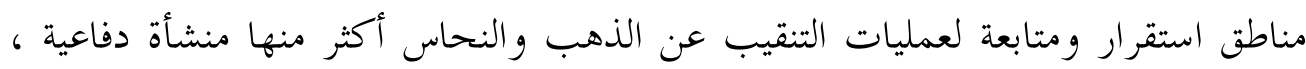
لقد كان الهدف الرئيسي هو حماية المصالح الاقتصادية أكثر من العسكرية (0) وفن الداخل بدا أن الجنود النوبيين اكتسبوا لأنفسهم مكانا داخل الجختمع المصري

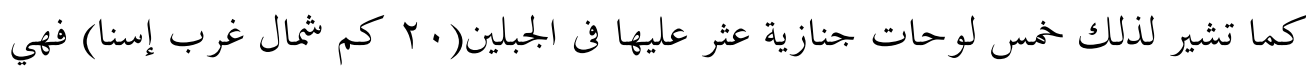
تدل على أن أصحاها النوبيين عاشوا ودُفنوا كجزء من المجتمع المصرى الذى خدمبوه و أهمى

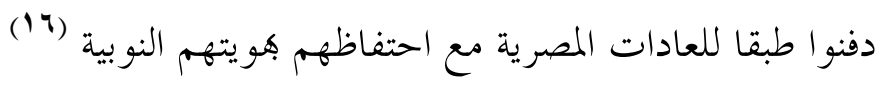

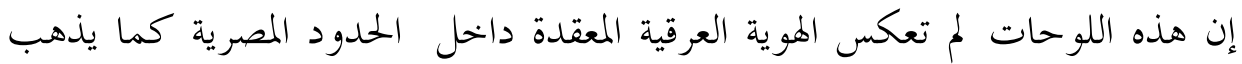
Ficher

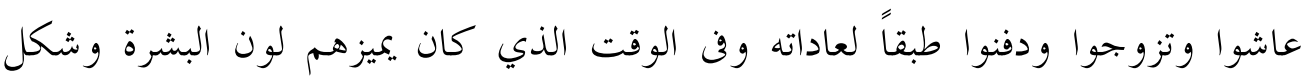
الملابس عن المصريين فقد صُورَت زوجاهم بالملابس وتصفيفات الشعر المصرية إن هذه

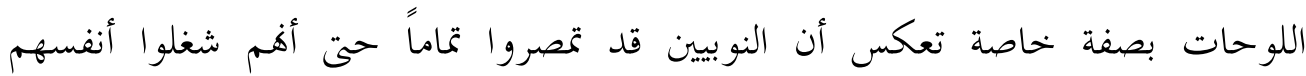

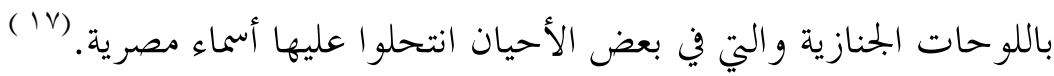


ومن مقبرة " مسحتي " في " مير " بأسيوط هناك نموذجان فريدان لفرقة نوبية

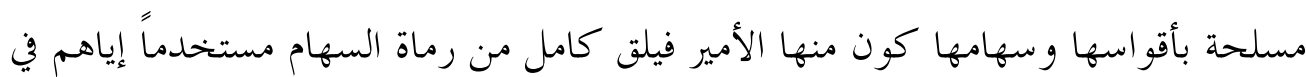
الإغارة ، ويتكون الفيلق من أربعين جنديا نُظموا في صفوف أربعة يحملون الأقواس ، ويحمل كل منهم قوسا وبعض السهام ، وقد ارتدي الجنود النوبيون مآزرهم المميزة، وفي

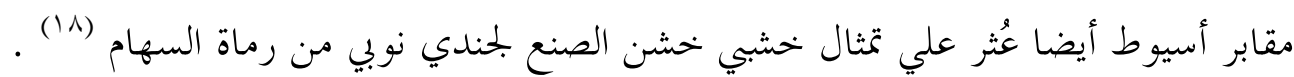

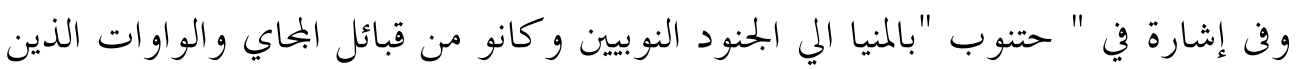
أشير إليهم بين أتباع مقاطعة " الأشمونين ـهرموبوليس " ، في في النقش المؤرخ بالسنة

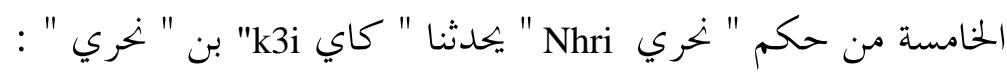
" سرت للحرب مع مدينتي وقد كنت أقوم بنصيي في المؤخرة ، مع أنه لم يكن معي غيري

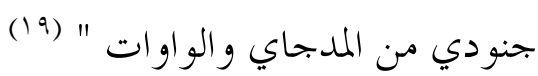

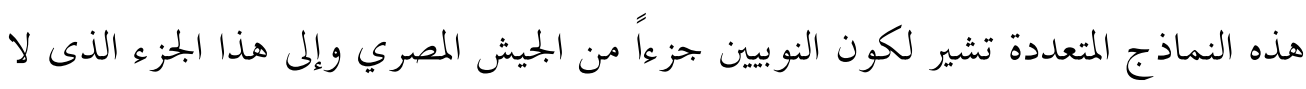

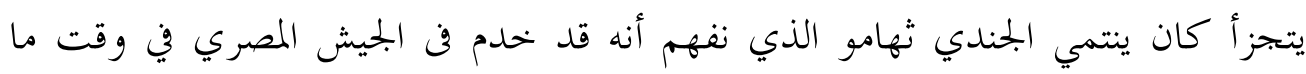
خلال عهد الملك "منتوحتب نب حبت رع" على وجه التحديد حيث نرى أسمه مذكورا

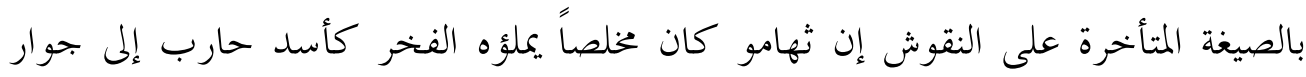

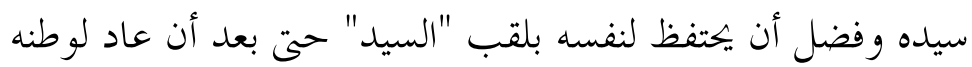

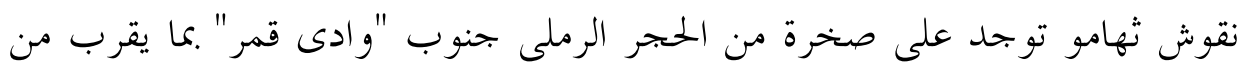

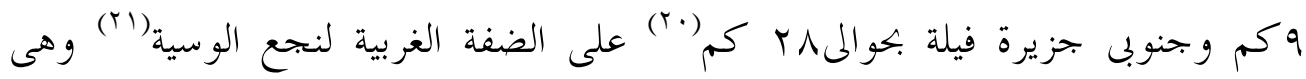

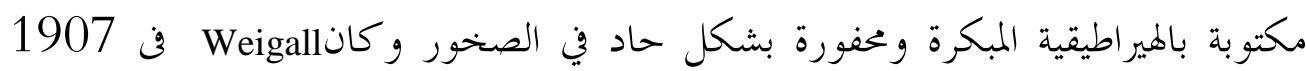

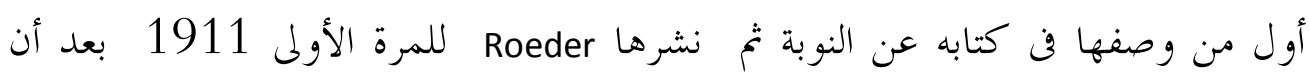

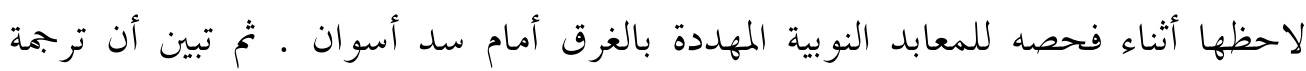
Söederbergh 1941,Winlock, اللغوية تواجه مشكلات. فقام كل من Roeder 1947

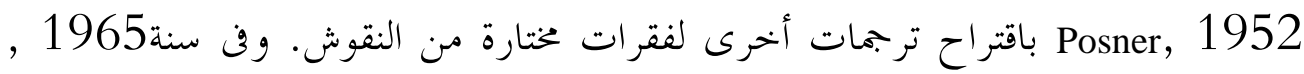
نشرSchenkel ترجمة منقحة لكل نقش و أزال أخطاء Roeder اللغوية في الترجمة.ثيم 


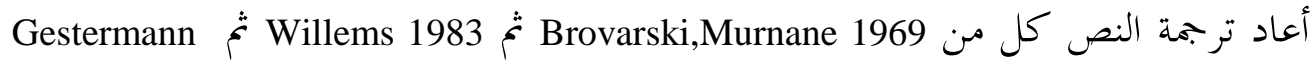

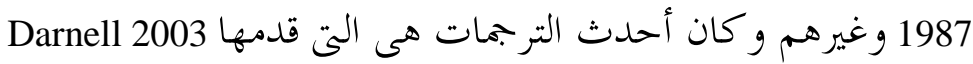
و النقش مقسم إلى سبعة أجزاء مكتوبة هيراطيقية مبكرة وترجع أحداث النقش إلى الى الفترة

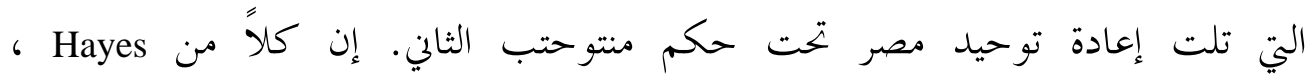
يعتقدون أها تنتمي إلى عصر سُمى بعصر التطهير؛ أي بعد انتصار (Tr) الأسرة الطيبية بينما Posner كلا من و ير جعها لفترة أطلقا عليها (الفوضى) التي قيل أها صاحبت

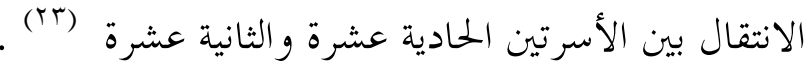

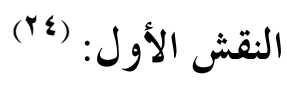

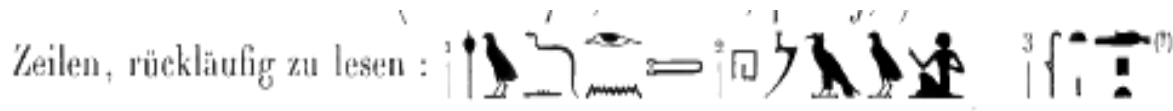
f

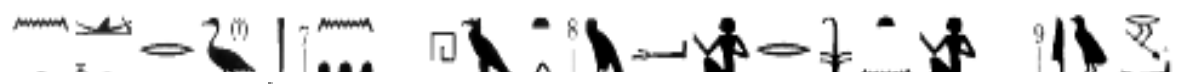
גin $=$ 口八

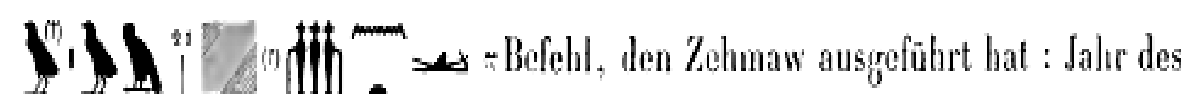

Wd ir nt thm3w / rnpt sḲr h 3st rnpt $3^{\mathrm{c}} / \mathrm{I}^{\mathrm{C}} \mathrm{h} 3 \mathrm{~m}$ ḥ 3 (3wf) Nb $\square \mathrm{pt} \mathrm{R}^{\mathrm{C}} \mathrm{m}$ $\mathrm{m} \Xi^{\complement}$ h nt.f.. r... B $\square$ n/ h $3 \mathrm{t} \mathrm{s} 3$ (i)m ${ }^{\mathrm{c}} \mathrm{i}$ r nswt .(i)iw h ni . n.f t3 $\square \mathrm{rg}$ r ff k3 n.f sm3/ ${ }^{\mathrm{C}} 3 \mathrm{mw} / \mathrm{d}$ 3ty hosf. s w3st / m bḥ $3 \square$ (i) n $\square$ sy / ir ${ }^{\mathrm{C}}$ nw ${ }^{\mathrm{C}} \square^{\mathrm{C}} \mathrm{n}$ sh r r n.f/ d 3ty .f3t .f h t3w m h ny

“نقش صنعه ثهامو في عام إخضاع الأراضي الأجنبية للجنوب لقد بدأت أحارب في

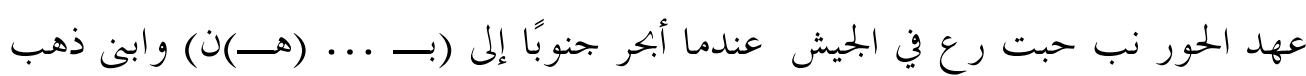

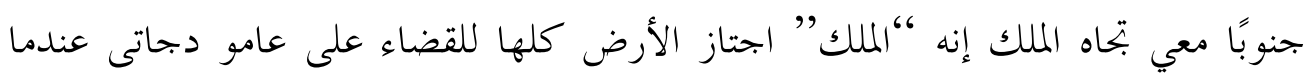


اقتربوا كانت طيبة في البحموعة إهم النوبيين الذين أحضروا النجدة ثم قضى هو على دجاتى

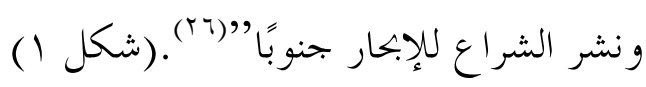

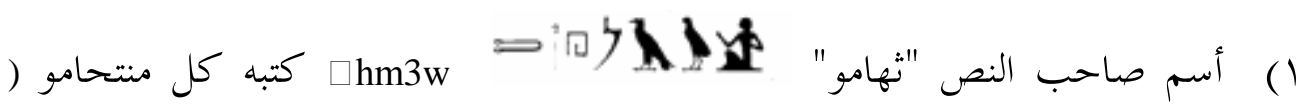
بينما أطلق عليه أخرون "دجامو" ولكن النطق المطابق للكتابة هو

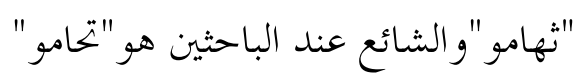

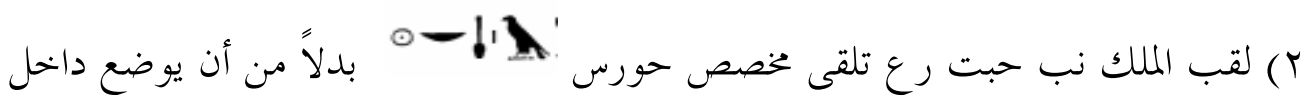
خرطوش وبالمثل كلمة nswt الملك فن السطر الثامن مكتوبة مكخصص بشرى أكثر

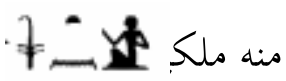

النقش هنا يكتبه جندى نوبى كمذكرات له وليس علينا أن نفترض أنه كان ملماً بالقواعد

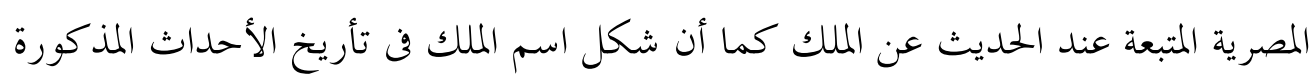
في النص ر.ما يكون صحيحًا فن سياق الكلام لنص رسمي يممل بوجه عام الألقاب الصحيحة ولكن في مثل هذا النص والذى يذكر فيه الملك فن السياق القصصي فيإن مثل هذه الشكليات تكون بعيدة الاحتمال خاصة وأن منتوحتب نب حبت رعن وع مر باثنين أو

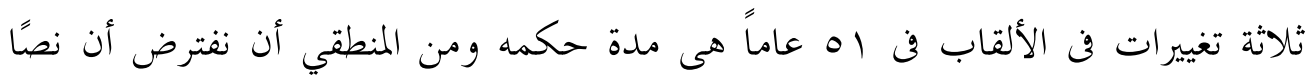

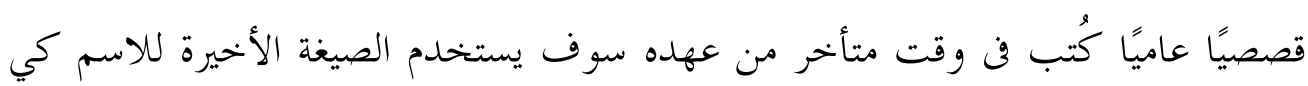

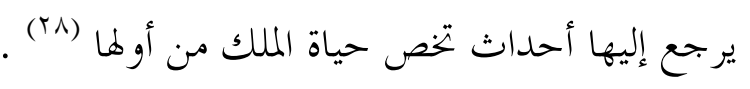

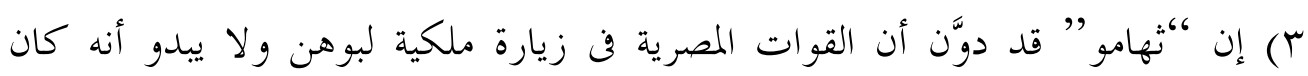
واحلًا من النوبيين الذين كانوا يقيمون في مصر خلال عصر الانتقال الأول فيبدو أنه دخل الخدمة المصرية مباشرة من موطنه والذي كان يعتبر واوات في تلك الفترة إن

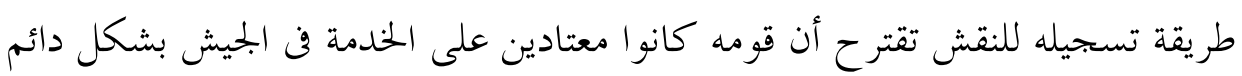

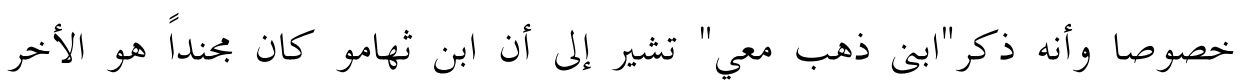

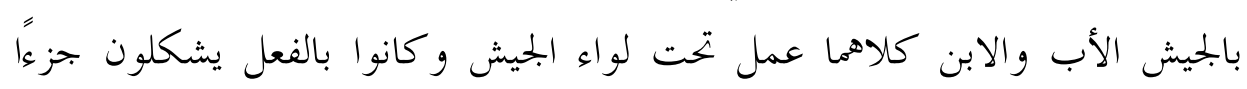
يعتمد عليه حكام مصر العليا. 
C3m ( ترجمتها الحرفية تعنى “الأسيويين” (T9) وهى هنا غير صحيحة خحاصة في نص

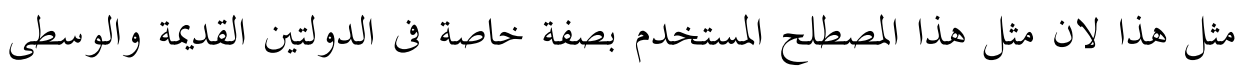

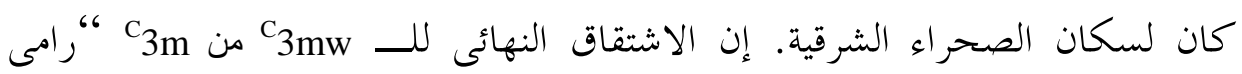

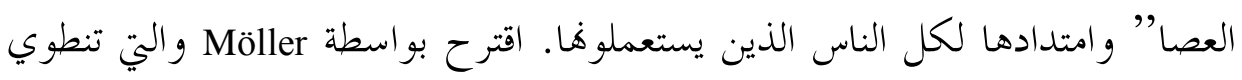

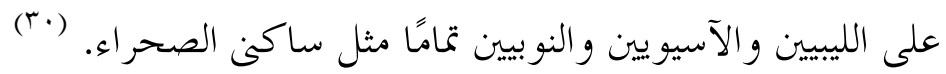
\3ty ربما تكون متطابقة مع $\square 3 t$ وهم محليون من واوات الجنوبية يظهرون بشكل

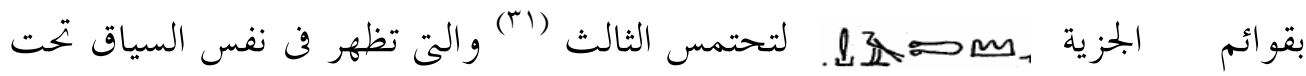

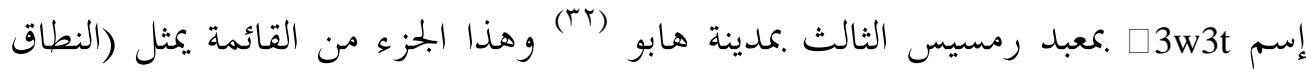
الجنوبى) لواوات فن ظهور لاحق لذلك الذي تتضمنه الحدود في الدولة الوسطى والتي كانت تقف عند سمنة وفى هذا الجزء من القائمة والذي يتضمن المنطقة بين الشلال الثاني

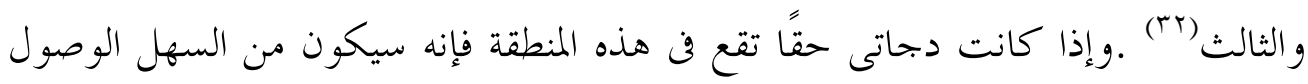

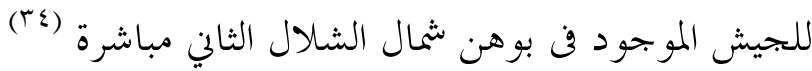

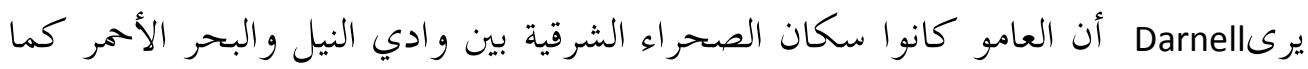

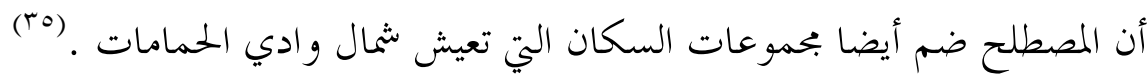

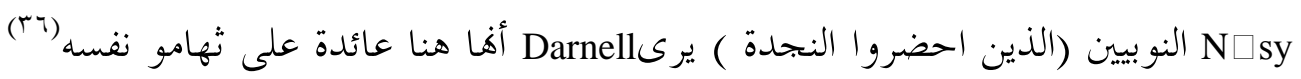

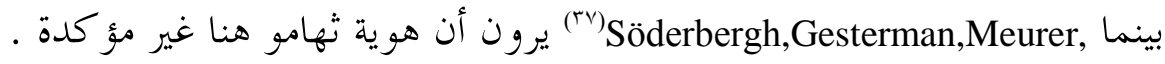

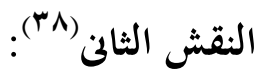
rechte - Zeilen: schliessen wohl an Nr. I an :

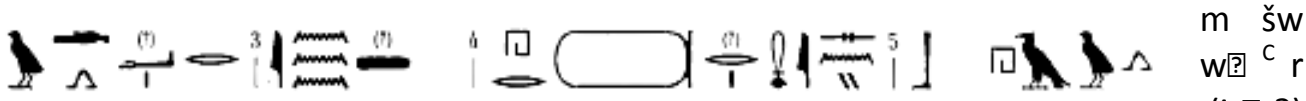

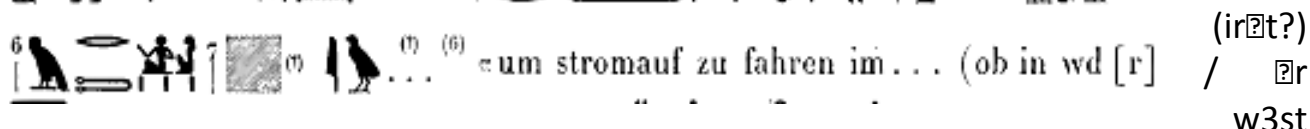
mi Kad.s ny bh3w.f m rmt ${ }^{(39)}$

“للجنوب / يرفع ذراعه/ ضد حاكم الأراضي .. يرضى الملك (؟) كما يكون

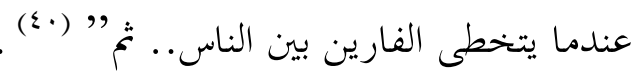




$$
\text { يرف w }{ }^{\mathrm{C}} \mathrm{C} \text { - }
$$

يقرأهاس3r) Brovarski\&Murnane (ir $\square$ t?) يضعان خرطوش داخل النص

يقرا أ Schenkel النقش بشكل عكسى مثل الأول لأنه في رأيه هذه الطريقة يكون النص ذا

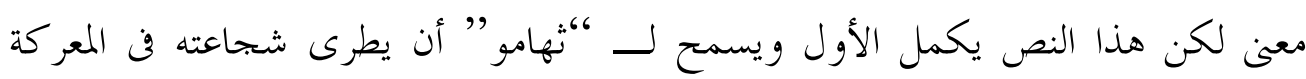

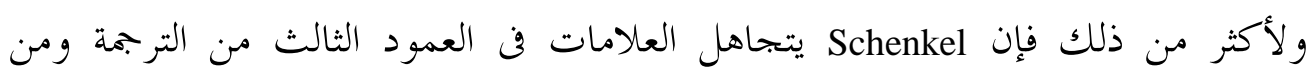
الواضح أها مشكلة ولكن بإعادة اختبار النقش نكشف وجودهم ويشير إلى أن القراءة تتم

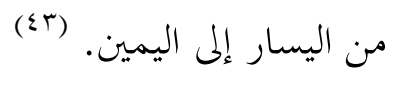

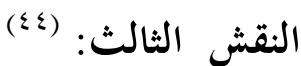

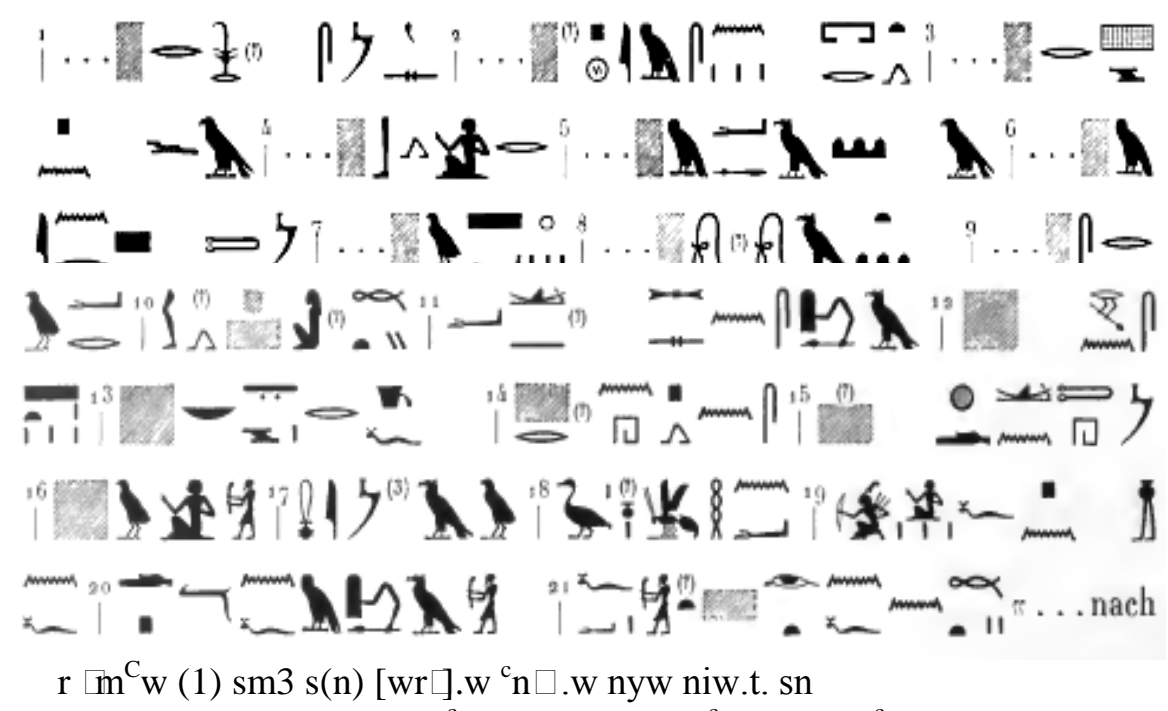

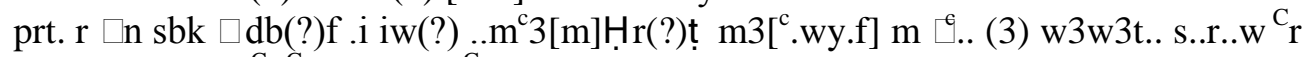
$\square$ r nsw.t m $\square$ ty ${ }^{{ }^{C}}{ }^{\mathrm{C}}$.n $\square$ s n.s ${ }^{C}$ h3wch 3.w tyw h n.s sp3wt. s nb t3 r d r ff r nh b n .s hd.$n t h m 3 w$ mi m3w s3r ${ }^{C}$ bity $\square n^{\mathrm{C}}(4) \mathrm{m}{ }^{\mathrm{C}} \mathrm{w}$.f pn in n. fdp n. f $\mathrm{m}^{\mathrm{C}} \mathrm{h}$.f nht $\mathrm{n}$ irt $\mathrm{n}$.f n m $\square$ ty

“إلى شمعو كى يخضع / ... معهم ذهب صاعدًا / في مو اجهة بحيرة سوبك.. لقد

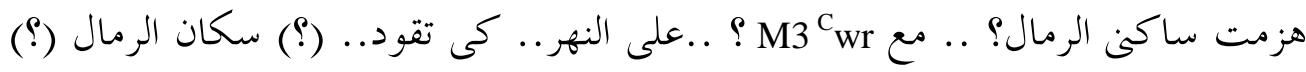

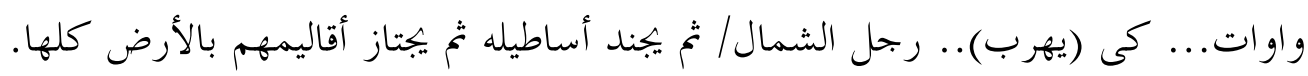

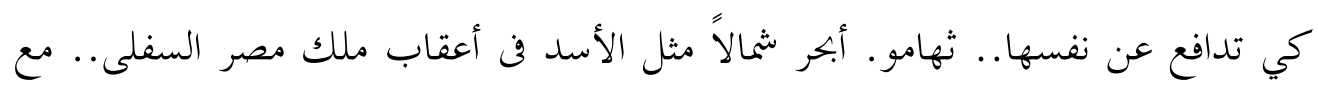


هذه .. جيشه الذى أحضره.. إنه ولوع بالقتال... وذراعه أصبح قويًا نتيجة ما فعله بالشمال (

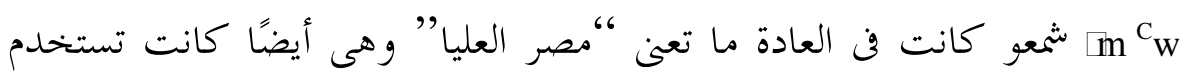

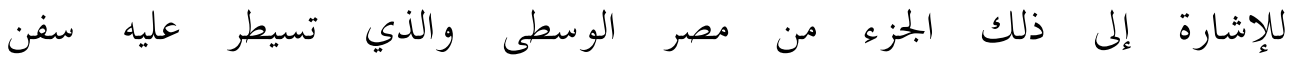

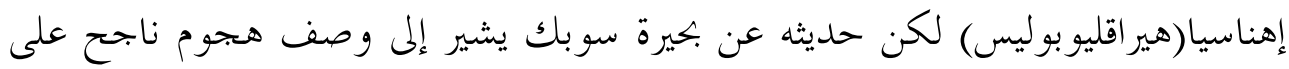

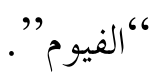

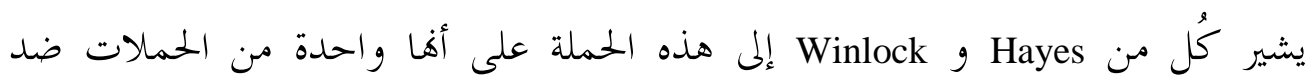

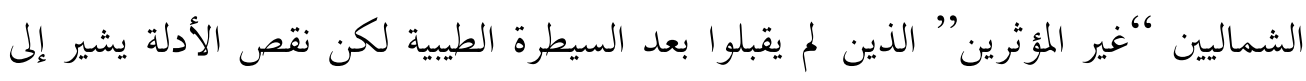

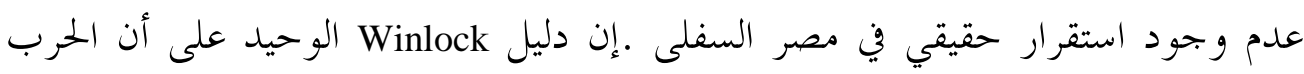

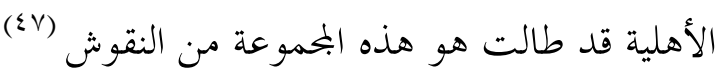

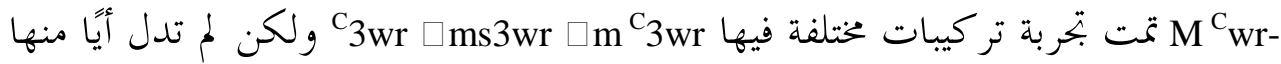

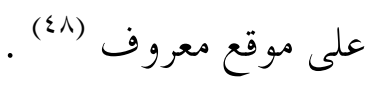
هنا ثهامو يفخر بنفسه لقد تبع سيده كأسد.

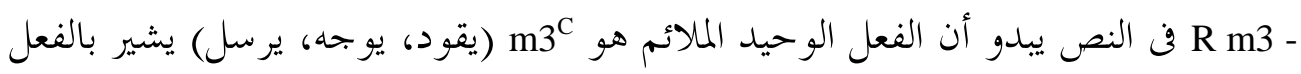

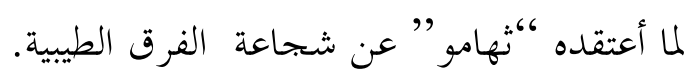

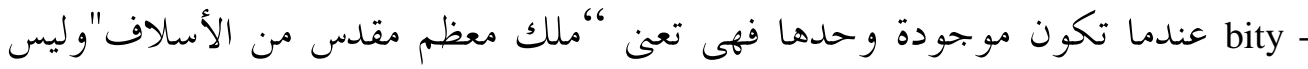

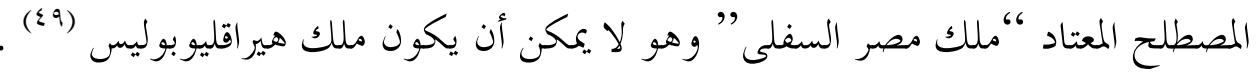

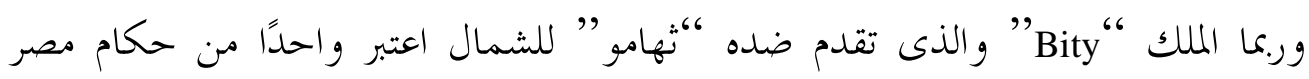

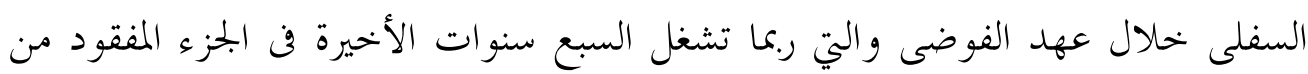

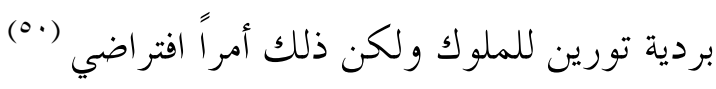


النقش الرابع: (1)

h3t rw / w3st $\square$ gmt .s / ${ }^{\mathrm{C}} \square^{\mathrm{C}}$ h r mrt k3.sn ${ }^{\mathrm{C}}$. 3w h r n rK w w ${ }^{\mathrm{C}}$ rw $\square$ r. i im. f

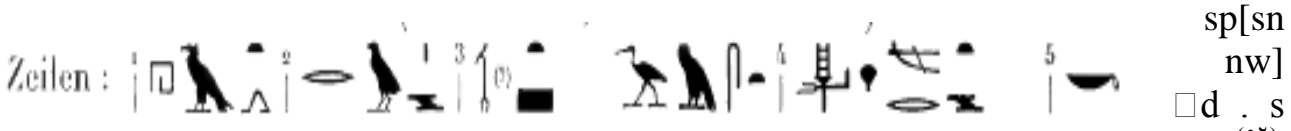

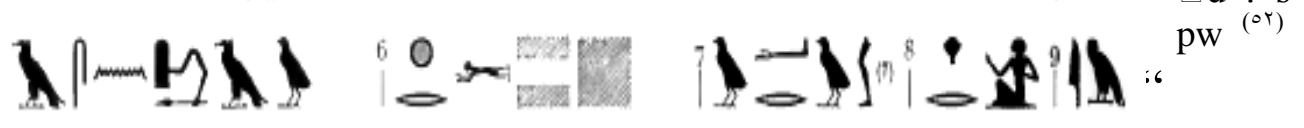

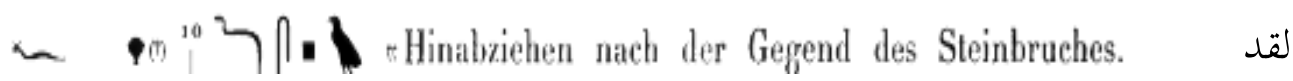
ذهبت جنوبًا. لمقاطعة طيبة فوجدهم و اقفين على ضفة النهر.. كانو ايخططون للحرب.. إن

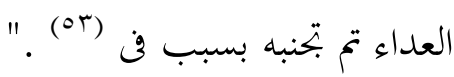

$$
\begin{aligned}
& \text { النقش الخامس: (\&) }
\end{aligned}
$$

m/w w3st. ${ }^{\mathrm{C}} \square^{\mathrm{C}} \mathrm{n}(1) \square \mathrm{r}$ iw $\square \mathrm{r}(\mathrm{t}) \square$ rw- $\square^{\mathrm{C}}$ w.s wn(i)r3 ${ }^{\mathrm{c}} 3 \mathrm{w} \square$ [spr.f] ${ }^{\text {(55) }}$

senkrechte $\longrightarrow$ Zeilen; am Anfang der Zeilen kann nichts fehlen : í

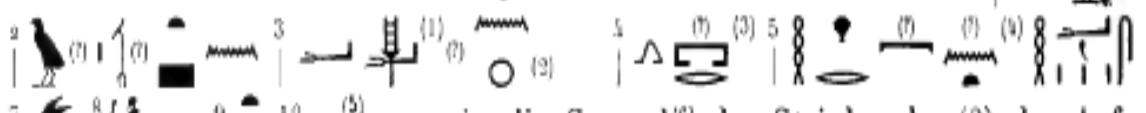

مقاطعة

طيبة /

عندما أتيت / في سلام / مع أهلها... لأنين / كنت قويًا بتحاه.. (أناس) (Tهن)

النقش السادس: (ov)

${ }^{(\circ \wedge)}$ mniw. $\square$ r/ $\square$ wt $\square$ idr/ink pw $\square$ hm3w 3 n.f

rechte $\rightarrow$ Zeilen, vollständig erhalten :

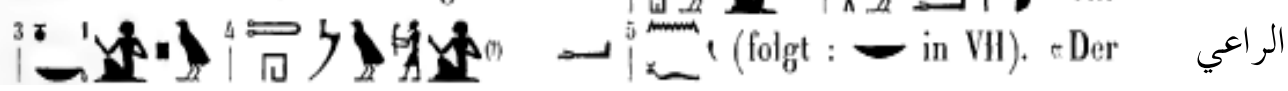

يقود

القطيع/ إنه أنا/ “ثهامو" "، الجريء الذي بمد الذراع “"نوى" (9ه)

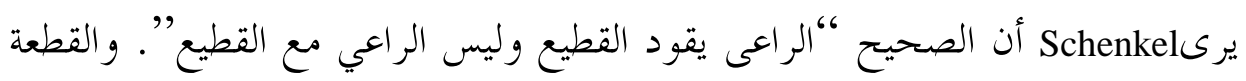

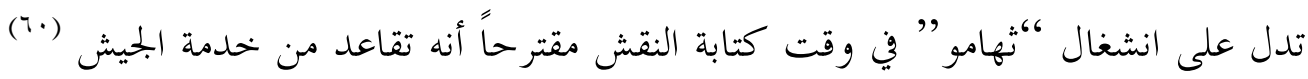


وربما النوبى المنتصر يشبه فن هاية نقشه صورة الراعي الذي يقود القطيع بالفرعون يسوق المتمردين أمامه وهو المنظر الذى نراه في الكرنك حيث سيتى الأول يأسر قادش، كما نراه في منظرين آخرين من عصر رمسيس الثاني ورمسيس الثالث في مدينة هابو هذا المنظر

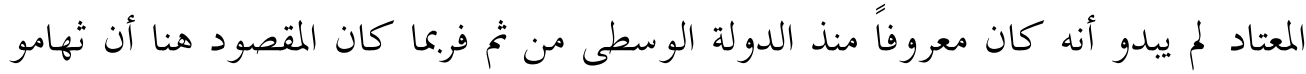

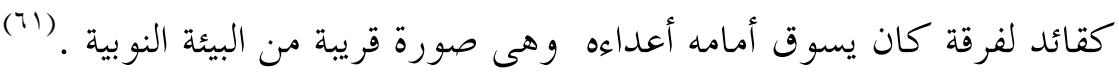

$\mathrm{nb} t \underline{\mathrm{h} m} 3 \mathrm{w} \square . \underline{\mathrm{d} d} \mathrm{~d}^{\mathrm{C}} \mathrm{nh}$ wd $\left.3 \mathrm{snb}{ }^{(7 r}\right)$

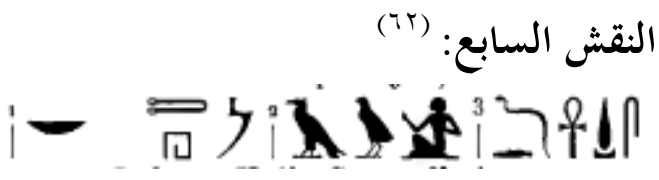

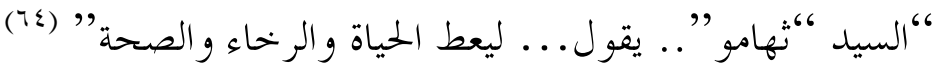
إن Roeder يلحق كلمة nb بنهاية السطر السادس معللاً ذلك بأن اللقب (سيد) قبل

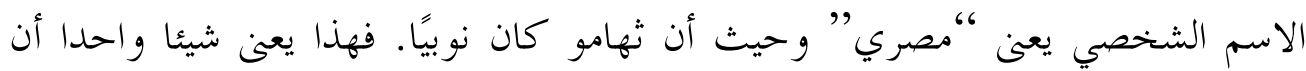
ثهامو أراد أن يحتفظ بلقب السيد بعد عودته لبلاده

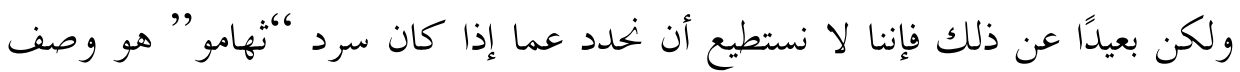
موجز أم سرد قصصي، فهو ييدو على كل الأحوال مطابقًا للطريقة المتبعة عند المصريين في الكتابة وإن كنا لا نستطيع أن بخزم عما إذا كان ثهامو هو الذي كتب لبع النص بنفسه أم إنه عهد بسيرته الشخصية إلى أحد الكتبة المتخصصين والذي من المحتمل أنه كان كاتب في الجيش و لم يحدد ثهامو من خحلال النص أي لقب خحاص به سواء داخل الجيش أو خارجهة (70)

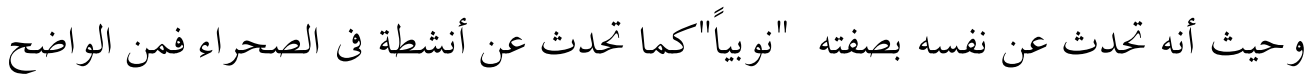
أنه قد أتى من الصحراء حتى أنه يمكننا إفتراض أنه ينتمي إلى بحموعة من محاربى الصحراء

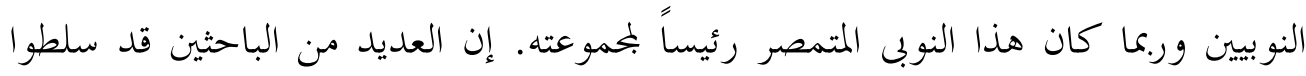
الأضواء على نقوش ثهامو لغويا بشكل كبير لكن ما كان يعنينا في نقوش ثهامو بالدرجة الأولى إنما هو ذلك الرضا الذي أبداه عن خدمته في الجيش وكيف تبع بلع مليكه إلى الشمال وفخره بشجاعته كمحارب نوبي عاد إلى وطنه يملؤه الفخر ليحتفظ لنفسه بلقب "السيد". 
1) Emry 1965:pp127 .

2) Adams 1977:pp141.

3) Emry 1965: pp127.

4) Adams 1977:pp165 .

5) Sethe,URK,1,pp211-2 .

6) Ficher. $1961:$ pp76

7) Sethe. URK, $1 \mathrm{pp} 101$

8) Breasted , J .1906: AR 1, pp. 142

9) Ficher. 1961: pp75 .

10) Gardiner, 1947: vol1 pp82-85 .

11) Wilkinson, 2005:pp147

12 ) Gardiner, 1947 vol1.pp82-85

13) Hassan,Giza VI ,pt3 Fig 127,130 .

14) Smith ,2003:pp 75.

15) Smith, 1991:pp 111 .

16) Ficher ,1961:pp44 .

17) Fischer , 1961:pp 56.

18) Scharff, A, 1936: p. 21 .

19) Anthes, 1928: pp. $35 \square 36$

20) Roeder, 1911: p. 104 .

21)Randell,2003:pp32

22) Winlock, 1947, p. 39 \& Hayes, 1971, I2, p. 20 \& Meurer 1996: pp78

23) Posner, 1951, p. 163-166 \&Peden 2001:pp24-25

24) Roeder, 1911 , pp. 104

25)Randell ,2003:pp33

27)Winlock, 1947: p. 31-32

26) Brovarski\&Murnane 1969, p. 11 Winlock 1947, p. 35

28) Gardiner, 1956: p. 42 .

29) Award, 1982: p. 72, n. 589 \& Hayes, 1955, p. 22

30) Möller, 1893: p. 123-24 .

31) Sethe,urk (IV) :798\#44 .

32)Wilson, 1936: pp. 32 .

33)Ernest, 1958, VI: pp. 20-21

34)Brovarski, \&Murnane 1969: pp. 13 .

35) Darnell,2003:pp37 not 13

36) Darnell,2003:pp37

37)Söederbrgh,1941:pp60\&Gestermann,L.1987:pp209

38)Roeder, 1911, pp. 104-5

39) Darnell,2003:pp33

40 )Bravarski, \&Murnane 1969, p. 11 Winlock, 1947, p. 35

41) wb I, 3.86, 16 .

42) Brovarski\&Murnane $1969: \mathrm{pp} 14$

43) Schenkel, 1965: pp. 274-77 .

44) Roeder, 1911, pp. 105-106.

45). Darnell,2003:pp33

46) Brovarski, \&Murnane 1969:pp. 14-15 .

47)Winlock, 1947: pp. 33.

48)Brovarski, \&Murnane 1969: pp. 14-15. 
49)Otto, 1960: pp. 143-51.

50)Posner, 1951: pp. 163-166 .

51) Roeder, 1911:pp106

52)Darnell,2003:pp43

53)Brovarski, \&Murnane 1969: pp. 16-17.

54) Roeder, 1911: pp. 107

55) Darnell,2003:pp

56) Brovarski, 1969: pp. 18-19

57)Roeder, 1911: pp. 107

58) Darnell,2003:pp45

59) Brovarski, \&Murnane 1969 :pp. 17 .

60)Schenkel, 1965: pp. 277

61)Darnell,2003:pp47

62) Roeder, 1911: pp. 107

63) Darnell,2003:pp47

64)Brovarski\&Murnane 1969:pp18-19

65) Darnell,2003:pp 47

- Adams W Y. 1977:Nubia: Corridor to Africa. Princeton,

- Anthes, R, Die Felseninchriften von Hatnub, Leipzig, 1928,

- Booth. C, 2005:The Role of Foreigners in Ancient Egypt: An Study of NonStereotypical Artistic Repre -sentations

- Brovarski\&Murnane 1969: Inscription from the time of $\mathrm{Nb}$ hpt $\mathrm{R}^{\mathrm{C}}$ Serapis I

- Brovarski 1985: The inscribed Materials of the first Intermediate Period from Naga El-Dêr A.J.A. n 89, N.Y.

- Breasted 1960: Ancient Records of Egypt, Vol. II, London.

- Butner,A.2007: The Rhetoric and the Reality Egyptian Conceptions of Foreigners during the MK (c. 2055-1650 BCE), Tennessee

- Darnell.J.C 2003:The Rock Inscriptions of Tjehemau at Abisko ,ZÄS 130

- Ernest 1958: countries of the Ethiopian Empire of Kash and Egyptian Old Ethiopian, Part II.

- Emery.W1965: Egypt in Nubia. London.

- Fischer, H.G, 1961: the Nubian Mercenaries of Gebelein during the First Intermediate Period, Kush, IX, Khartoum,

- Faulkner R.O. 1964, A Concise dictionary of Middle Egyptian.London,

- Gardiner A. 19" 47, Ancient Egyptian Onomastics, 3 vols, Oxford.

- Gardiner A. 1956: The First King Mentuhotp of the Eleventh Dynasty MDAIK (14). Cairo.

- Gardiner A. 1961, Egypt of the Pharos, Oxford.

- Gauthier 1929:Dictionnaire des noms géographiques 6 vols .le Caire

- Gestermann,L.1987:Kontinuität und Wandel in Politik 


\section{د /حسنى عبد الرحيم حسن}

und Verwaltung des frühen Mittleren Reiches in Ägypten GOF,18 Wiesbaden

- Lepsius 1879-1913: Den Kmöler aus Aegyptan und Aethiopien Vol. 2, Leipzig.

- Meurer.G1996:Nubier in Ägypten bis zum Beginn des neuen Reiches MDAIK13 1996

- Môller, WM 1893: A Sien and Eoropa, Berlin

- lange \& Schefer 1908: Graba and Denksteine de Mittleren Reiches I, Berlin.

- Otto E. 1958: Agypten Der Wegdes Pharaone Nreidris, Stuttgart.

- Otto E. 1960: Das Gerbauch des König titles bity, ZÄS n 89

- Peden.A.J2001:the graffiti of pharaonic Egypt .Probleme der Ägyptologie 17

- Posner 1951: Review on Stock Bi Or 8, Leiden.

- Posner 1952: Apropos de grafiti d Abisco Ar-Or 20.

- Ranke H. 1949: Die Agyptischen Personennamen 2 vols. wiesbaden

- Roeder G. 1911: Debod bis Bab Kalabsche.

- Scharff, A, 1936: Der Histoische Abschnitt der Lehre für König Merikare, Müchen,

- Schenkel 1965, Memphis, Hera Kleopolis, Theben, Wiesbanden.

- Sethe K 1903: Urkunden des Alten Reichs Leipzig.

- schiffer agarate und gebil dent name de Mentohotop ZÄS 62, Leipzig.

- Smith. S .T. 2003:Wretched Kush: Ethnic Identities and Boundaries in Egypt's Nubian Empire. London

- Söeve Söederbrgh, 1941: Agypten und Nubien .

- Spiegelberg 1921: Aegyptische und andere Graffitie ausdesthebunischess, Necropolis.

- Weigall A. 1907: Antiquties of Lowers Nubia.

Weigall A. 1906-7:A report on the Antiquities of Lower Nubia Oxford Wilkinson,T.2005: "Dictionary of Ancient Egypt", Thames \& Hudson Ltd

- Winlock H. 1947: The Rise and Fall of the Middle Kingdom In Thebas, N.Y.

- Willems,H.O,1983:"The Nomarchs of the Hare Nome and Early Middle Kingdom history "JEOL.28 


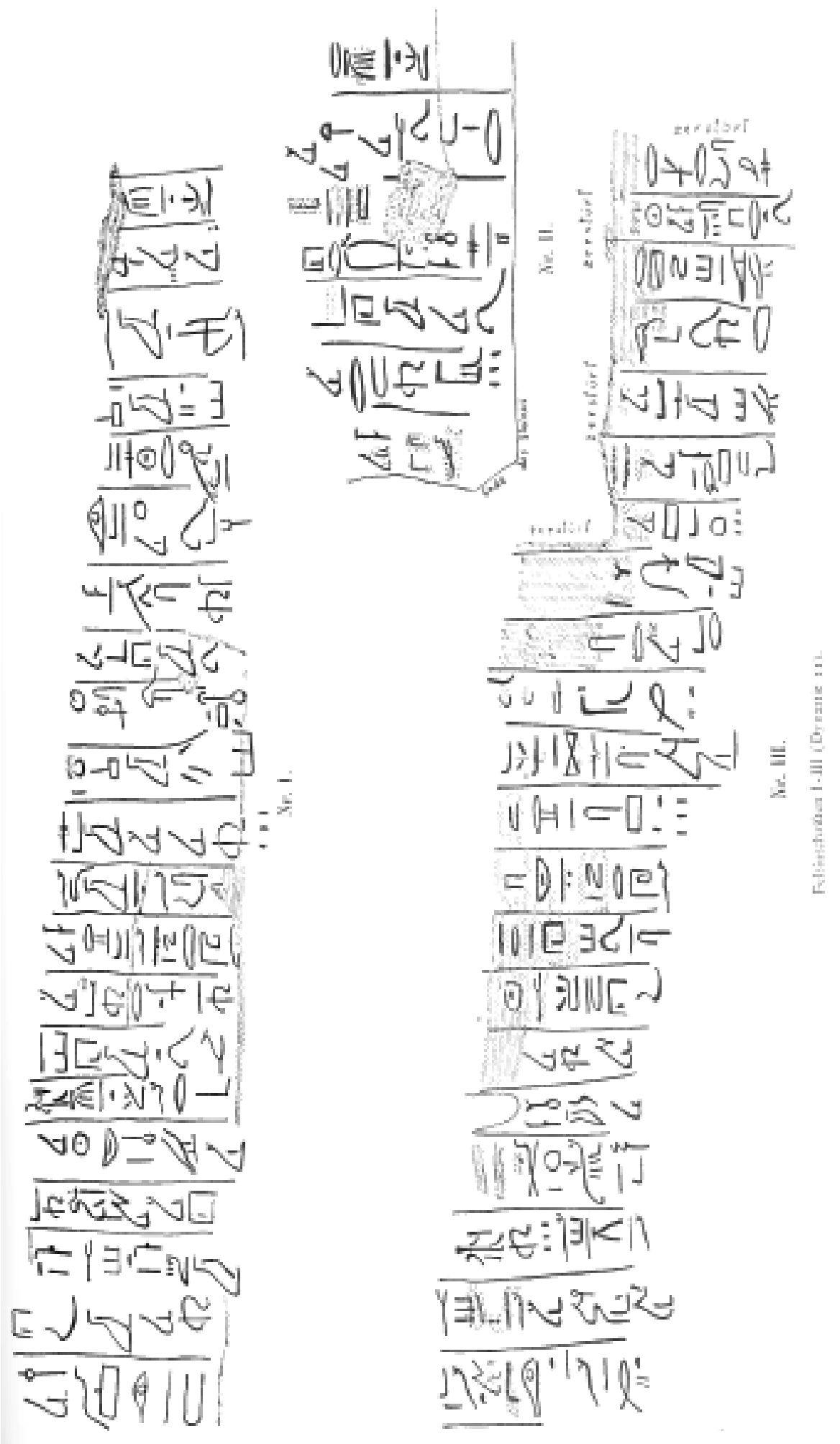

Weigall 1906:A report on Antiquities of Lower شكل(1) النقش 


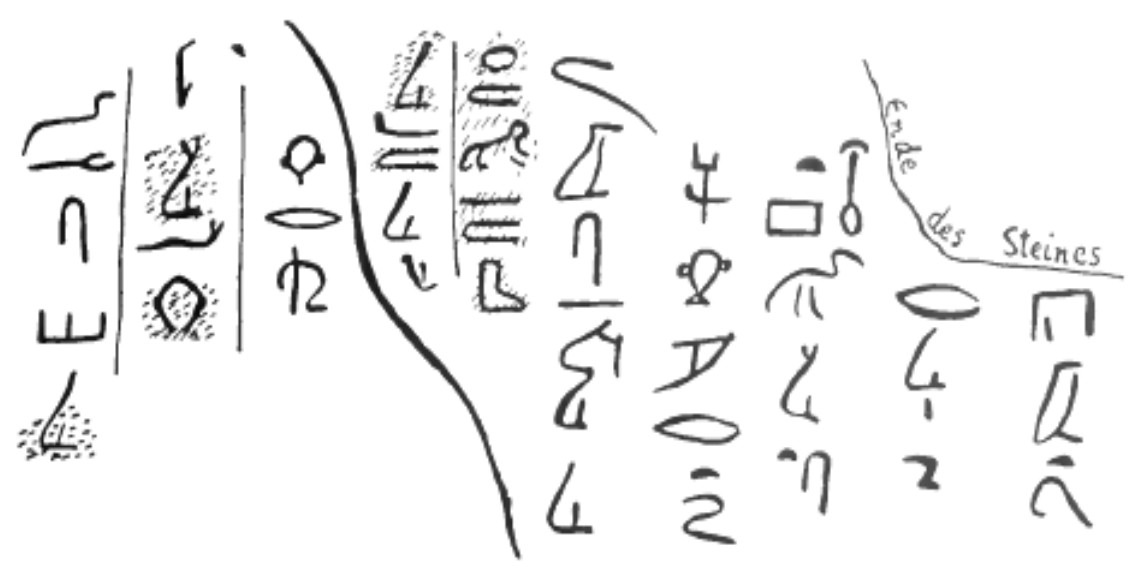

Nr. IV. a

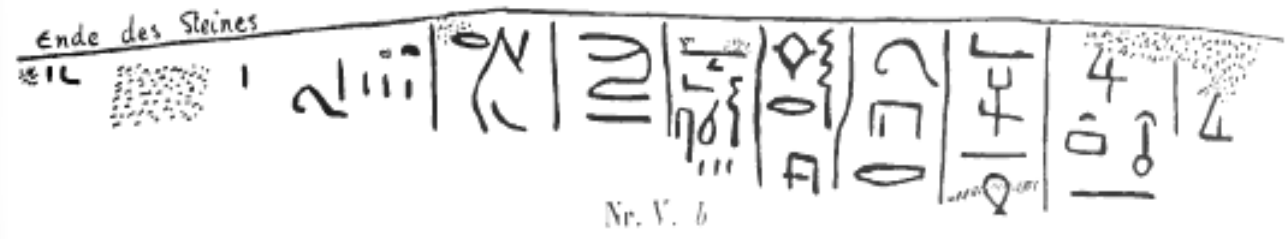

Nubia 1-2-3

Weigall 1906:A report on Antiquities of Lower Nubia॰- شكل (广) النقشين ع

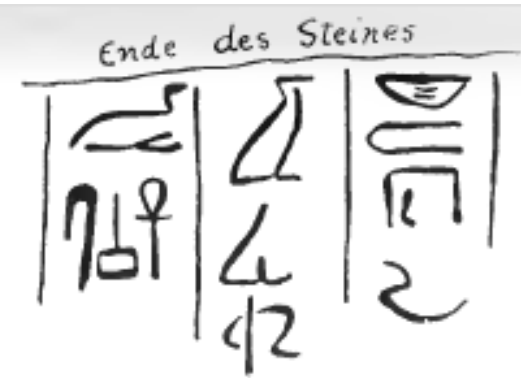

i (Nr. V'II)

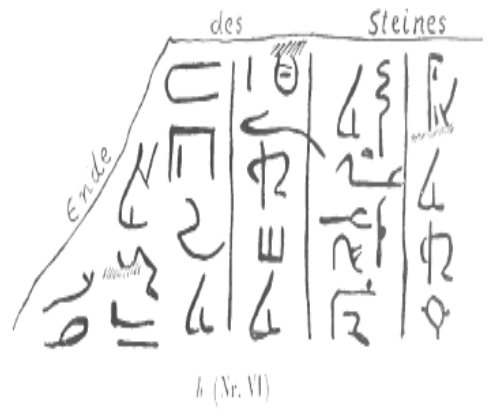

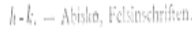


نقوش الجندى النوبى (ثهامو)

Weigall 1906:A report on Antiquities of Lower Nubia` - شكل (Yr) النقشين

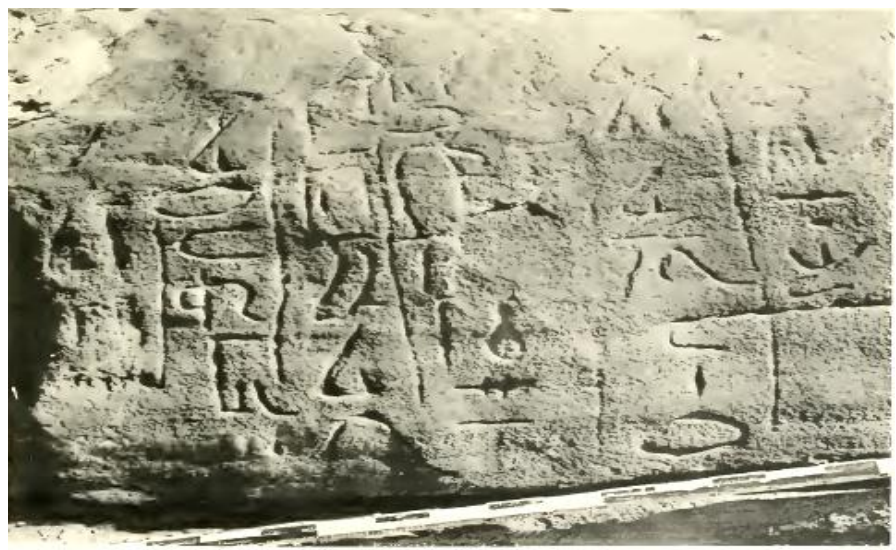

النقش الثنان

Roeder ,1911: Debod bis Bab Kalabsche.
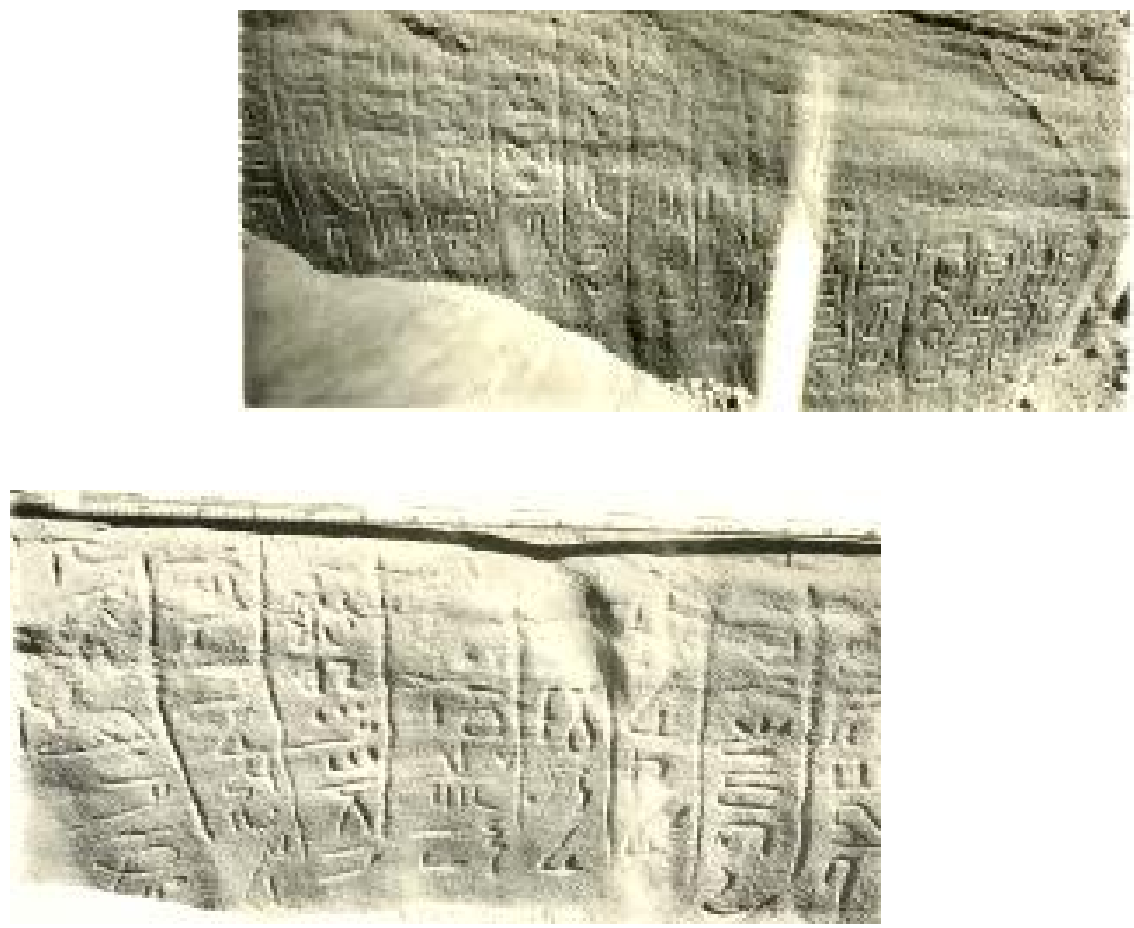

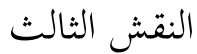


Roeder ,1911: Debod bis Bab Kalabsche.

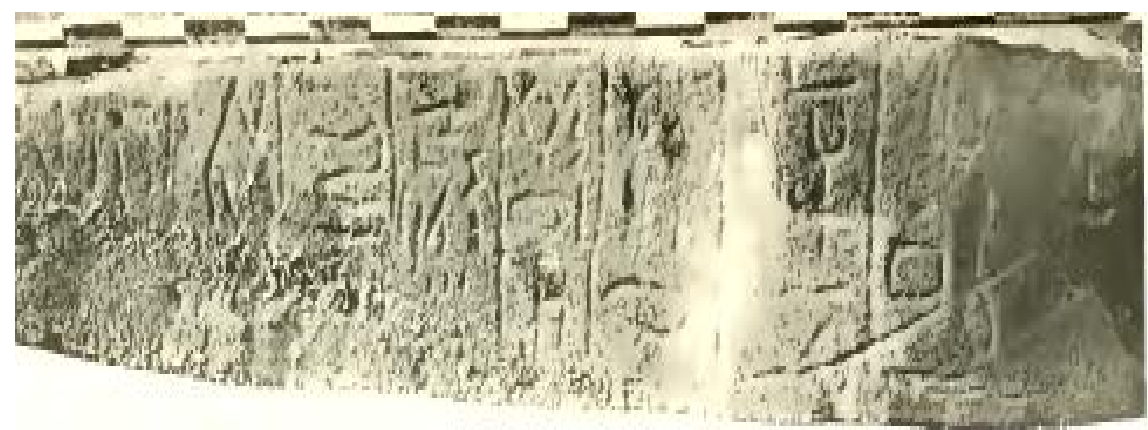

النقش الخامس

Roeder ,1911: Debod bis Bab Kalabsche

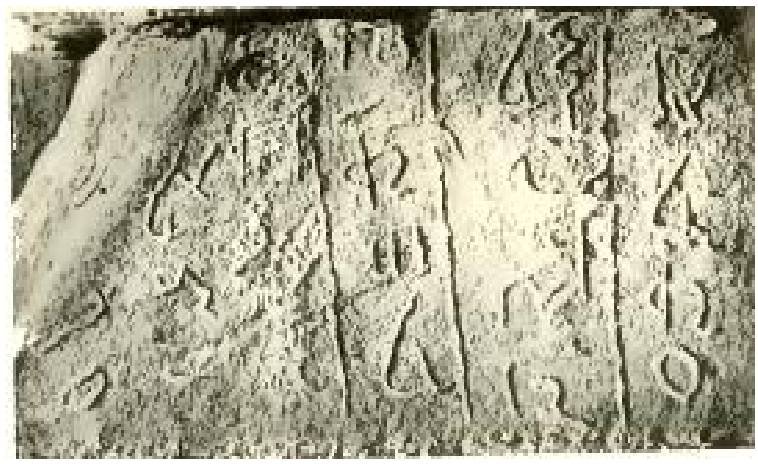

النقش السادس Roeder ,1911: Debod bis Bab Kalabsche

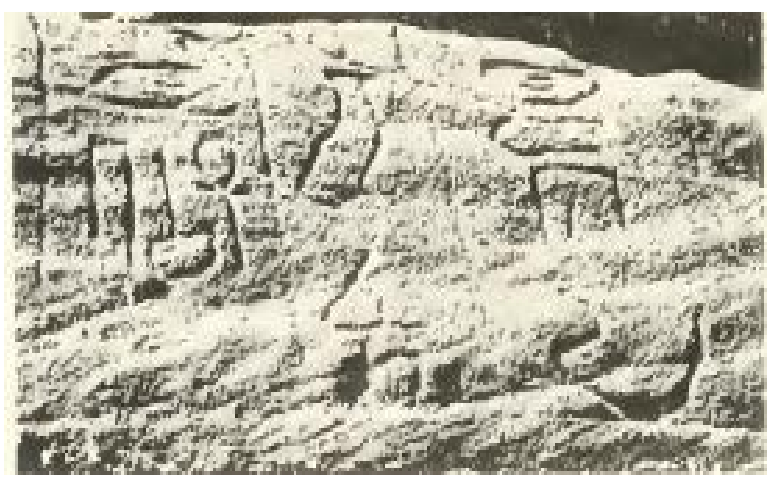

النقش السابعe Roeder ,1911: Debod bis Bab Kalabsche 